Jurnal ABDINUS : Jurnal Pengabdian Nusantara, 2 (2), 2019, 197-206

Available online at: http://ojs.unpkediri.ac.id/index.php/PPM

DOI: https://doi.org/10.29407/ja.v2i2.12595

\title{
Pendampingan Pembuatan LKS Berorientasi Metakognisi Pada Guru Sekolah Dasar Muhammadiyah 5 Batu
}

\author{
Ichsan Anshory AM${ }^{1}$, Delora Jantung Amelia ${ }^{1}$, Setiya Yunus Saputra ${ }^{1}$ \\ Ichsan@umm.ac.id, delorajantung@umm.ac.id, setiyayunus@umm.ac.id \\ ${ }^{1}$ Program Studi Pendidikan Guru Sekolah Dasar \\ ${ }^{1}$ Universitas Muhammadiyah Malang
}

Received: 2111 2018. Revised: 2812 2018. Accepted: 16012019

\begin{abstract}
Implementation, Community Service Program With the Title "Ibm Assistance Group for Making LKS Based on Metacognition in Elementary School Teachers" begins with a workshop providing material for making worksheets and material on metacognition. This activity involved collaboration with partner schools namely SD Muhammadiyah 5 Kota Batu. In this service the teacher appointed was all teachers ranging from class I teachers to class VI teachers, the principal of Muhammadiyah 5 Elementary School also participated in this activity. For the sake of the creation of this service program all teachers need to gain reinforcement of concepts and material about making worksheets, learning activities and practice questions that are oriented to metacognition, with the provision of material reinforcement the optimal LKS will be made. Furthermore, the activities carried out were assistance in making LKS. This activity was carried out by the way the dedication team came to partner schools. The dedication team checks the drafts made by the teachers, sees the progress that has been made, and discusses the obstacles faced by the teacher in preparing the LKS. The worksheets produced here are metacognitiveoriented LKS so that all activities in the LKS must reflect LKS-oriented activities starting from their activities and the questions in them. As the end of the series of programs this service is the gathering of LKS oriented to metacognition. LKS collected is LKS that has been checked by the service team and has been revised by the teachers. Improvement notes are discussed together, with the aim of preparing a follow-up plan.
\end{abstract}

Keywords: Mentoring, LKS, Metacognition

\begin{abstract}
Abstrak: Pelaksanaan, Program Pengabdian Masyarakat dengan judul "Ibm Kelompok Pendampingan Pembuatan LKS Berbasis Metakognisi Pada Guru Sekolah Dasar" diawali dengan workshop pemberian materi pembuatan LKS dan materi metakognisi. Kegiatan ini melibatkan kerjasama degan sekolah mitra yaitu SD Muhammadiyah 5 Kota Batu. Pada pengabdian ini guru yang ditunjuk adalah seluruh guru mulai dari guru kelas I sampai dengan guru kelas VI, kepala sekolah SD Muhammadiyah 5 juga mengikuti kegiatan ini. Demi terciptanya program pengabdian ini seluruh guru perlu mendapatkan penguatan konsep dan materi tentang pembuatan LKS, kegiatan pembelajaran dan soal latihan yang berorientasi metakognisi, dengan adanya pemberian penguatan materi maka pembuatan LKS akan terlaksana semakin optimal. Selanjutnya kegiatan yang dilakukan adalah pendampingan pembuatan LKS. Kegiatan ini dilakukan dengan cara tim
\end{abstract}




\section{Jurnal ABDINUS : Jurnal Pengabdian Nusantara, 2 (2), 2019, 197-206}

Ichsan Anshory AM, Delora Jantung Amelia, Setiya Yunus Saputra

pengabdian datang ke sekolah mitra. Tim pengabdian mengecek draft yang telah dibuat oleh guru-guru, melihat kemajuan yang telah dicapai, serta diskusi tentang kendala-kendala yang dihadapi guru dalam menyusun LKS. LKS yang dihasilkan disini merupakan LKS yang berorientasi metakognisi sehingga seluruh kegiatan yang ada pada LKS tersebut harus mencerminkan berorientasi LKS yang dimulai dari kegiatannya dan soal-soal di dalamnya. Sebagai akhir dari rangkaian program pengabdian ini adalah pengumpulan LKS berorientasi metakognisi. LKS yang dikumpulkan adalah LKS yang telah dicek oleh tim pengabdian dan telah direvisi oleh guru-guru. Catatancatatan perbaikan didiskusikan bersama, dengan tujuan untuk menyusun rencana tindak lanjut.

Kata Kunci: Pendampingan, LKS, Metakognisi

\section{ANALISIS SITUASI}

Pendidikan di era globalisasi lebih menekankan dan berfokus kepada Siswa (student centered). Paradigma tersebut secara langsung mengubah pola pikir seluruh komponen yang terkait dengan sekolah. Peran guru dalam pembelajaran saat ini lebih menjadi fasilitator siswa. Kentungan yang didapatkan, siswa dengan pemikirannya sendiri mengkonstruksi sebuah pemahaman terkait dengan pengetahuan dalam pembelajaran di sekolah dengan panduan guru. Dalam Data yang ditunjukkan buletin pimpinan wilayah Muhammadiyah Jawa Timur, menyatahkan bahwa sekolah-sekolah yang menjadi amal usaha Muhammadiyah yang berada di daerah Malang hanya berjumlah 6 sekolah. Sekolah tersebut diantaranya yaitu SD Muhammadiyah 1, 3, 4, 5, 7, 8, dan 9. SD Muhammadiyah 5 yang terletak di Bumiaji Kota Batu adalah Sekolah Dasar yang berada di bawah naungan lembaga Muhammadiyah yang terletak di Kota Batu, SD tersebut merupahkan salah satu amal usaha organisasi Muhammadiyah.

SD Muhammadiyah 5 Batu merupakan Sekolah Dasar yang tergolong cukup muda dan mulai berdiri. Tahun 2017 Tim PGSD melakukan observasi pada SD tersebut sehingga dapat diketahui dengan jelas keperluan yang sangat dibutuhkan oleh SD Muhammadiyah 5 dalam kegiatan pembelajaran. Kurikulum yang digunakan pada Sekolah Dasar tersebut adalah kurikulum KTSP, namun mulai menyongsong penerapan kurikulum 2013 pada seluruh kelasnya pada tahun 2018. Kurikulum 2013 menggunakan pendekatan saintifik dimana siswa dituntut untuk mampu menemukan sesuatu berdasarkan penalarannya sendiri. Pembelajaran metakognisi sejalan dengan penerapan kurikulum 2013 khususnya pendekatan saintifik yaitu pembelajaran yang berfokus siswa dan menciptakan kemandirian serta keaktifan siswa. Untuk mempersiapkan penerapan kurikulum 2013 secara menyeluruh, SD Muhammadiyah 05 Kota Batu memerlukan dukungan bahan ajar yang disesuaikan dengan kebutuhan siswa. 


\section{Jurnal ABDINUS : Jurnal Pengabdian Nusantara, 2 (2), 2019, 197-206 \\ Ichsan Anshory AM, Delora Jantung Amelia, Setiya Yunus Saputra}

Pada penerapan Kurikulum 2013 (k13) siswa dituntut untuk lebih kreatif dan lebih mandiri dalam pembelajaran di kelas. Peran guru sangat tinggi untuk dapat menjamin kemandirian siswa. Pembiasaan kemandirian siswa perlu adanya dukungan dari pihak sekolah dalam manajemen pendidikan sekolah. Manajemen pendidikan dilakukan guna meningkatkan kualitas dan mutu. Dalam hal ini lembaga di bawah naungan Muhammadiyah khususnya Universitas Muhammadiyah Malang memiliki kewajiban mengamalkan bidang pendidikan. Sesuai dengan Rencana Induk Penelitian Universitas Muhammadiyah Malang 2014, bahwa Universitas Muhammadiyah Malang berperan aktif dalam pendidikan berkelanjutan yang dibutuhkan masyarakat, membudayakan kerja sama dalam satu disiplin maupun multi disiplin.

Berdasarkan kondisi tersebut di atas, maka sangat diperlukan suatu kegiatan pendampingan tentang pembuatan LKS berbasis metakognisi yang ditujukkan kepada guru. LKS berbasis metakognisi adalah suatu Lembar Kerja Siswa yang inovatif dibuat oleh guru untuk memfasilitasi siswa agar mampu lebih mandiri dan aktif dalam menyelesaikan tugastugas belajarnya dalam rangka mencapai prestasi belajarnya.

\section{SOLUSI DAN TARGET}

Pengabdian ini dilakukan untuk membuat LKS berbasis metakognisi untuk mengembangkan kemandirian serta kontrol diri siswa terhadap tugas-tugas belajarnya. Metode penelitian yang digunakan adalah metode penelitian kualitatif dengan menggunakan rancangan penelitian deskriptif. Metode penelitian kualitatif adalah metode yang lebih menekankan pada aspek pemahaman secara mendalam terhadap suatu masalah daripada melihat permasalahannya. Sedangkan penelitian deskriptif adalah penelitian yang bertujuan untuk mengumpulkan dan mendeskripsikan data.

Penelitian ini melibatkan peneliti dalam proses penelitian dari awal sampai dengan akhir dengan hasil penelitian berupa laporan. Subjek penelitian ini adalah guru kelas tinggi di SD Muhammadiyah 05 Kota Batu. Sedangkan objek pada penelitian ini adalah pembelajaran yang akan dilakukan dengan menggunakan bahan ajar LKS. Data dalam penelitian ini terbagi menjadi dua bagian yaitu data primer dan data sekunder.

Prosedur dalam penelitian ini yaitu pertama adalah analisis kurikulum dilakukan dengan cara melakukan pengkajian terhadap kurikulum yang telah ditetapkan. Identifikasi tujuan umum pembelajaran yaitu meliputi identifikasi KI dan KD yang sesuai dengan sub tema yang akan di ajarkan kepada siswa. KI dan KD yang telah diidentifikasi tersebut 


\section{Jurnal ABDINUS : Jurnal Pengabdian Nusantara, 2 (2), 2019, 197-206}

Ichsan Anshory AM, Delora Jantung Amelia, Setiya Yunus Saputra

selanjutnya dikembangkan menjadi bahan ajar LKS berbasis metakognisi. Setelah LKS berbasis metakognisi dirancang maka akan diaplikasikan dalam kegiatan pembelajaran.

Langkah-langkah analisis data sebagai berikut:

1. Menelaah semua data tentang pembuatan LKS berbasis metakognisi dan penerapannya dalam pembelajaran di kelas untuk meningkatkan aktivitas belajar siswa. Hasil penelaah ini berupa deskripsi pembuatan LKS berbasis metakognisi dan aspek aktivitas serta kemandirian siswa di SD Muhammadiyah 5 Bumiajai.

2. Mentranskripkan kelemahan-kelemahan dan kekurangan pendampingan pembuatan LKS berbasis metakognisi.

3. Melakukan verifikasi (penarikan kesimpulan) dari data yang sudah diklasifikasikan dan ditraskripkan pada penyajian data.

Kegiatan IbM pembuatan Lembar Kerja Siswa memberikan solusi kegiatan di bawah ini.

1. Workshop pembuatan LKS berorientasi metakognisi

Pada pengabdian ini hal pertama yang dilakukan adalah melakukan kegiatan workshop, tim pengabdian akan melaksanakan workshop dengan peserta seluruh guru SD Muhammadiyah 5 Kota Batu. Materi workshop meliputi cara pembuatan lembar kerja siswa, pembuatan kegiatan pembelajaran dan soal yang berorientasi metakognisi.

2. Pendampingan pembuatan lembar kerja siswa

Para peserta pengabdian akan mendapat pendampingan dari tim pengabdian sejumlah 3 orang, pendampingan dilakukan secara maksimal. Pendampingan dilakukan untuk menyusun lembar kerja siswa berorientasi metakognisi. Pendampingan tidak hanya dilakukan secara tatap muka saja tetapi juga bisa dilakukan via email atau whatsapp.

3. Refleksi dan tindak lanjut

Catatan-catatan perbaikan akan didiskusikan bersama dan dijadikan rujukan untuk menyempurnakan LKS yang telah disusun oleh seluruh guru SD Muhammadiyah 9 Kota Batu.

\section{PELAKSANAAN}

Pendampingan pengembangan kegiatan pembelajaran dengan menggunakan LKS berbasis metakognisi. Oleh karena itu tim pelaksanaan pengabdian terdiri dari dosen bidang Pendidikan Guru Sekolah Dasar yang disesuaikan dengan bidang kajian penelitian yang diusulkan. 
Jurnal ABDINUS : Jurnal Pengabdian Nusantara, 2 (2), 2019, 197-206

Ichsan Anshory AM, Delora Jantung Amelia, Setiya Yunus Saputra

Tabel 1. Jenis Kegiatan

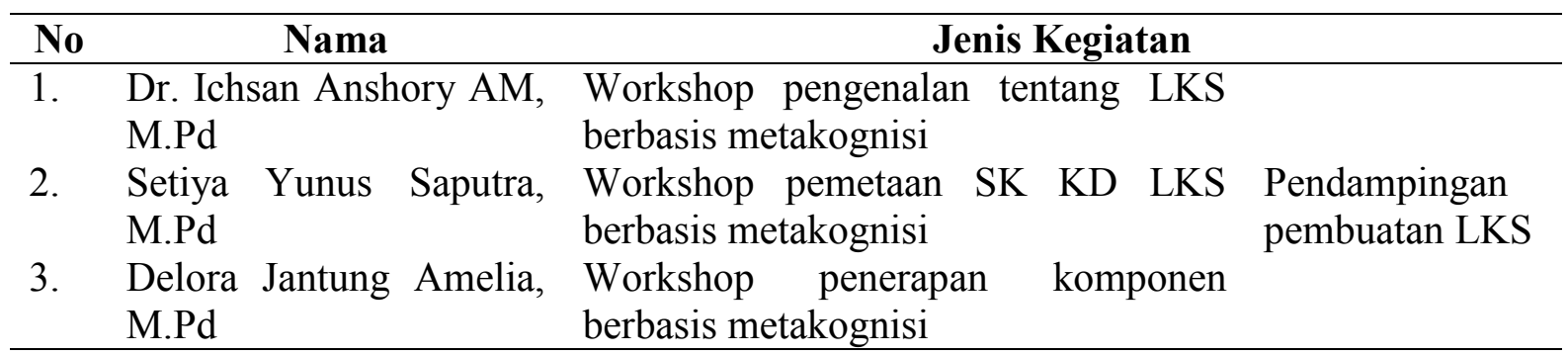

Pada kegiatan pengabdian Pendampingan pemuatan Lembar Kerja Siswa dibagi dalam beberapa kegiatan yang mana kegiatan tersebut sudah dilaksanakan yang dipaparkan dalam beberapa kegiatan di bawah ini:

1. Rapat Kordinasi

Sebelum melakukan pengabdian kepada masyarakat tim pengabdian melakukan rapat kordinasi dengan tim pengabdian guna merancang jadwal maupun materi yang akan dipaparkan.

a. Pelaksanaan Rapat Kordinasi 1

Pada tanggal 12 Januari 2018 di kantor PGSD, rapat dilakukan dengan tujuan koordinasi yang kedua ini bertujuan untuk merancang jadwal kegiatan pengabdian yang terdiri dari 3 tahap yaitu workshop, pendampingan dan pelaksanaan pembelajaran di kelas serta kegiatan refleksi. Selain itu, juga dilakukan persiapan kegiatan sosialisasi ke sekolah tempat pengabdian. Dalam rangka kegiatan sosialisasi maka dilakukan pembagian tugas untuk kegiatan sosialisasi ke sekolah. Pembagian tugas meliputi penyelesaian administratif serta menghubungi pihak sekolah berkenaan dengan jadwal sosialisasi.Pelaksanaan

b. Rapat Kordinasi 2

Pada tanggal 6 Februari 2018 bertepat di SD Muhammadiyah 5 Kota Batu, tim pengabdian dan kepala sekolah berkordinasi terkait teknis pelaksanaan pendampingan.

c. Pelaksanaan Rapat Kordinasi 3

Pada tanggal 28 Juli 2018 di kantor PGSD diadakan rapat terkait refleksi dari semua hasil kegiatan pengabdian.

2. Workshop Pembuatan LKS Berorientasi Metakognisi

Penyelenggaraan workshop pembuatan Lembar Kerja Siswa berorientasi metakognisi dilakukan di SD Muhamamdiyah 5 Kota Batu. Tim pengabdian masyarakat dilakukan oleh 3 dosen FKIP UMM yang terdiri dari Ichsan Anshory, Delora Jantung Amelia, 


\section{Jurnal ABDINUS : Jurnal Pengabdian Nusantara, 2 (2), 2019, 197-206 \\ Ichsan Anshory AM, Delora Jantung Amelia, Setiya Yunus Saputra}

Setiya Yunus Saputra. Workshop dilakukan bertujuan untuk memahamkan guru-guru peserta pelatihan pembuatan Lembar Kerja Siswa, yang mana pada workshop ini ada beberapa materi yang dipaparkan oleh tim pengabdi kepada guru-guru SD Muhammadiyah 5 Kota Batu.

Workshop pembuatan Lembar Kerja Siswa dilaksanakan pada tanggal 23 Mei 2018 di SD Muhammadiyah 5 Kota Batu dengan pemateri Dr. Ichsan Anshory, AM. M.Pd (Materi 1 Lembar Kerja Siswa), Delora Jantung Amelia, M.Pd (Materi 2 Metakognis) serta, Setiya Yunus Saputra, M.Pd (Materi 3 LKS berorientasi metakognisi). Kegiatan ini bertujuan untuk membangun pemahaman peserta tentang cara pembuatan Lembar Kerja Siswa berorientasi metakognisi, selama ini peserta pelatihan hanya mengandalkan Lembar Kerja Siswa yang dibeli dari penerbit yang sudah ada dan beredar di sekolah-sekolah, yang mana isinya tidak seluruhnya mencerminkan kemampuan tertinggi siswa. Dengan adanya pendampingan pembuatan Lembar Kerja Siswa berorientasi metakognisi diharapkan para guru-guru dapat membuat LKS sendiri dengan begitu dapat mengakomodir kemampuan tertinggi siswanya.

Kegiatan workshop ini dimulai dari perancankan materi workshop yang disusun oleh tim pengabdian dibantu oleh mahasiswa, kemudian pemateri satu persatu memaparkan materi yang telah disiapkan, setelah pemaparan materi dibukalah sesi tanya-jawab yang diperuntukan untuk peserta yang belum pahan akan penjelasan yang telah dipaparkan. Pelaksanaan workshop memberikan pengalaman, wawasan dan pemahaman cara membuat LKS yang sesuai dengan kemampuan tertinggi siswa. Pelaksanaan workshop ini berlangsung selama 1 hari yang mana acara ini dihadiri oleh seluruh guru beserta kepala sekolah SD Muhamamdiyah 5 Kota Batu. Pada kegiatan ini dibahas dan dipaparkan secara mendalam tentang konsep LKS, teori metakognisi serta cara pembuatan LKS berorientasi metakognisi.

Pada akir kegiatan ini, tim pengabdian membuat rencana untuk mengujicobakan LKS metakognisi kepada salah satu siswa, atau uji dengan skala kecil, hal ini untuk mengetahui sejauh mana keberhasilan guru dalam membuat LKS berorientasi metakognisi. Pada perencanaan yang disusun guru-guru yang mengikuti membuat LKS berorientasi metakognisi pada kelas tinggi hal ini didasarkan karena pada kelas awal masih sedikit susah untuk menentukan kemampuan tertinggi siswa.

\section{HASIL DAN LUARAN}

Kegiatan selanjutnya setelah workshop adalah kegiatan pendampingan pembuatan Lembar Kerja Siswa oleh guru SD Muhamamdiyah 5 Kota Batu, guru-guru akan mendapatkan pendampingan secara maksimal. Pendampingan di lakukan oleh seluruh tim 


\section{Jurnal ABDINUS : Jurnal Pengabdian Nusantara, 2 (2), 2019, 197-206}

Ichsan Anshory AM, Delora Jantung Amelia, Setiya Yunus Saputra

pengabdian. Pendampingan dilakukan sebanyak dua kali, yang mana jadwal penampingan dilakukan sesuai dengan kegiatan yang ada di sekolah tersebut.

Hasil pendampingan dijelaskan dalam pemaparan di bawah ini:

1. Pendampingan 1

Pendampingan pertama dilakukan pada tanggal 25 Mei 2018 penampingan pertama difokuskan bagaimana cara menyusun membuat LKS (Lembar Kerja Siswa). Adapun kemajuan peserta:

a. Peserta sudah memahami bagaimana membuat soal yang sesuai dengan metakognisi.

b. Peserta pendampingan pembuatan Lembar Kerja Siswa sudah mampu mengembangkan soal yang dimulai dari kompetensi dasar kemudian disesuaikan dengan tujuan pembelajaran.

c. Soal yang dibuat sudah sesuai dengan karakteristik siswa dan lingkungan sekitar.

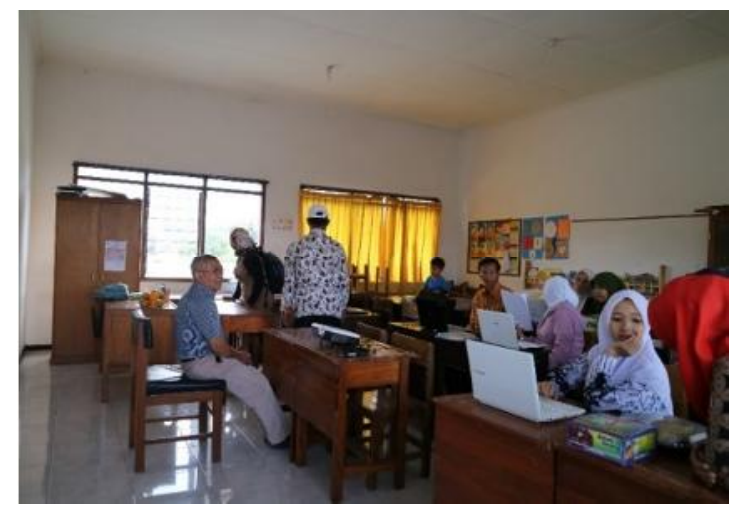

Gambar 1. Pemberian Materi Workshop LKS

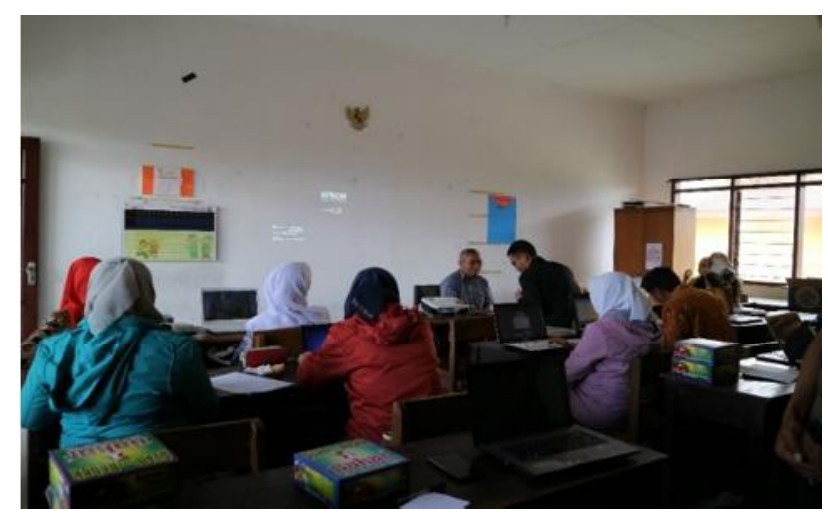

Gambar 2. Pembuatan LKS

2. Pendampingan 2

Pendampingan ke dua dilakukan pada tanggal 5 Juni 2018. Pendampingan ini dimaksudkan untuk memberikan masukan terhadap Lembar Kerja Siswa yang telah dibuat oleh peserta pendampingan. Adapun rincian dan masukan pembuatan Lembar Kerja Siswa yang telah dibuat oleh guru-guru yang dipaparkan di bawah ini:

a. Rata-rata pembuatan Lembar Kerja Siswa cover pembuatannya mengambil cover yang sudah ada, pada cover tidak tercantum tema yang di kembangkan dalam LKS.

b. Soal masih belum terpaparkan dengan benar, masih ada beberapa soal yang pembuatannya menjadi multitafsir, pemaparan materi masih dipaparkan.

c. Dari segi penulisan font kurang menarik, masik terkesan formal, banyak gambar yang tidak terdapat termuat sumbernya. 


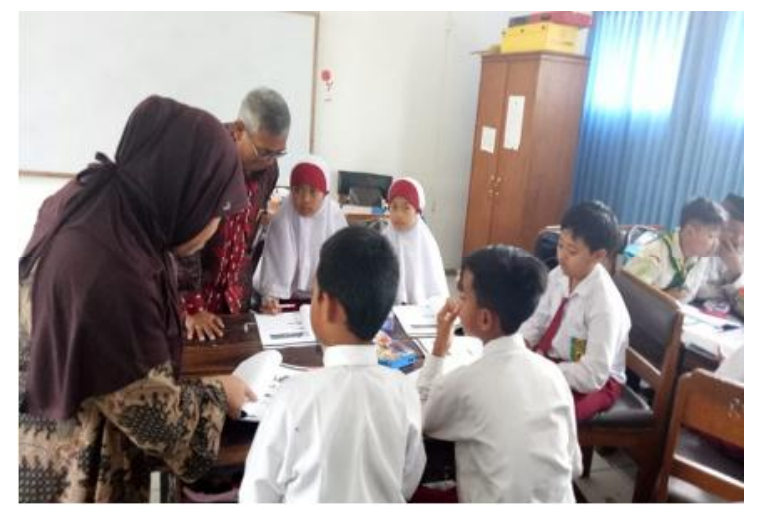

Gambar 3. Uji Coba Pembuatan LKS Kepada Siswa

Proses uji coba Lembar Kerja Siswa Dilakukan oleh guru kelas 4. Adapun rincian awal penguji cobaan akan dipaparkan mulai dari awal pembelajaran guru mengajak siswa mengaitkan pengetahuan siswa yang sudah dimiliki, guru bertanya kepada siswa kita tinggal di Kota Mana, seperti apa kota yang kita tinggali? Siswa menjawab dengan sangat antusias. Kemudian selanjutnya pertanyaan tentang buah apa yang terkenal di kota kita, siswa menjawab lagi dengan beberapa nama buah yang melekat, guru memberikan penguata terhadap jawaban siswa. Setelah itu siswa diminta keluar kelas untuk mengamati tumbuhan apa saja yang ada di sekitar lingkungannya, siswa mengamati tumbuhan yang ada pada sekitar sekolahan. Guru tidak mengarahkan siswa, karena salah satu bentuk teori metakognisi adalah siswa memahami kemampuan diirinya sendiri. Agar pembelajaran semakin efektif guru membentuk beberapa kelompok, yang mana kelompok sangat beragam tingkat pemahamannya.

Guru ingin melihat tingkat pemahaman siswa yang tertinggi, guru meminta siswa untuk mengisi Lembar Kerja Siswa yang telah di buat oleh guru yang mana kegiatannya ada mengamati, ada menggambar hasil pengamatan, serta menjawab soal. Adapun kegiatan tersebut dikerjakan secara individu dan kelompok. Setelah waktu diskusi dan pengerjaan LKS baik secara individu maupun kelompok, guru membahas jawaban siswa dengan beberapa penguatan.

Pendampingan pembuatan lembar kerja berbasis metakognisi akan membantu guru untuk membuat sendiri lembar kerja yang sesuai dengan kebutuhan siswa yang di ajarnya. Pembuatan Lembar Kerja Siswa ini juga didasarkan pada karakteristik siswa. Lembar kerja berorientasi metakognisi merupakan lembar kerja yang dapat meningkatkan kemampuan berpikir kritis siswa, siswa menjadi lebih aktif selama kegiatan berlangsung dikarenakan lebih banyak soal yang mengarah pada kegiatan secara terpraktekkan, siswa lebih bayak mengeksplore materi bersama dengan teman-temannya dan guru secara langsung, banyak 


\section{Jurnal ABDINUS : Jurnal Pengabdian Nusantara, 2 (2), 2019, 197-206 \\ Ichsan Anshory AM, Delora Jantung Amelia, Setiya Yunus Saputra}

kegiatan yang dilakukan secara bersama-sama sehingga menambah rasa percaya diri siswa, siswa lebih paham dan atas apa yang dikerjakan karena siswa terlibat secara langsung, serta siswa dapat mengetahui kemampuan tertinggi yang dimilikinya. Secara keseluruhan dari kegiatan pendampingan pembuatan Lembar Kerja Siswa di SD Muhammadiyah 5 Kota Batu berlangsung dengan baik dan lancar. Pada mulanya guru-guru disana belum mengerti cara membuat Lembar Kerja Siswa, akan tetapi dengan adanya kegiatan pendampingan pembuatan guru-guru bisa membuat LKS yang sesuai dengan karakteristik siswa, sesuai kebutuhan dan yang paling terpenting dapat membuat lembar kerja sesuai dengan tingkatan tertinggi siswa.

\section{SIMPULAN}

Secara keseluruhan dari kegiatan pendampingan pembuatan Lembar Kerja Siswa di SD Muhammadiyah 5 Kota Batu berlangsung dengan baik dan lancar. Pada mulanya guruguru disana belum mengerti cara membuat Lembar Kerja Siswa, tidak membuat peserta pelatihan (guru-guru SD Muhammadiyah 5 Kota Batu). Kegiatan pendampingan ini dapat lebih intesnsif lagi karena banyak guru-guru yang belum paham bagaimana pembuatan Lembar Kerja Siswa.

\section{DAFTAR PUSTAKA}

Anderson, L.W. \& Krathwohl, D.R. 2001. Kerangka Landasan Untuk: Pembelajaran, Pengajaran, dan Asesmen. Terjemahan Agung

Berk, L.E. 2010. Development through the Lifespan: Dari Prenatal Sampai Remaja (Transisi Menjelang Dewasa). Terjemahan Daryatno. 2012. Yogyakarta: Pustaka Belajar.

Galton, M. 2007. Learning and Teaching in the Primary Classroom. Great Britain: Sage Publication.

Jager, B.D., Jansen, M. \& Reezigt, G. 2005. The Development of Metacognitiopn in Primary School Learning Environments School Effectiveness and School Improvement, (Online), 16(2): 179-196., (http://202.116.45.198/xxjy/xxjy2/content/wenjian/ckwx/y/7/1.PDF), diakses 29 September 2016.

Kuhn, D. \& Dean, D. 2004. Metacognition: A Bridge between Cognitive Psychology and Educational Practice. Theory into Practice, (Online), 43(4): 268-273, (https://www.researchgate.net/publication/232869320_Metacognition_A_Bridge_Bet ween_Cognitive_Psychology_and_Educational_Practice), diakses 1 Oktober 2015. 
Lai, E.R. 2011. Metacognition: A Literature Review Research Report, (Online), (http://www.pearsonassessment.com/.research), diakses 1 Oktober 2016.

Prihantoro. 2015. Yogyakarta: Pustaka Belajar.

Rukminingrum, Dyah Vija. 2016. Pengetahuan Metakognitif Belajar Peserta didik Kelas V SD (Studi Kasus di SDN Pagergunung 03 Kabupaten Blitar). Tesis: Universitas Negeri Malang. 